\title{
EL LUGAR DE LA JUSTICIA EN LA FORMACIÓN DEL JURISTA ${ }^{1}$
}

\author{
Ángeles López Moreno \\ Catedrática. Departamento de Filosofía del Derecho, Moral y Política I \\ Facultad de Derecho de la Universidad Complutense de Madrid \\ angeleslo@der.ucm.es
}

Queridos colegas, mi punto de partida es más bien melancólico. Después de más de cuarenta y cinco años, y no muy lejana ya la jubilación, he aquí que, día tras día y clase tras clase, sigo y seguimos amarrados los profesores de las llamadas «ciencias de la cultura o del espíritu» a la tarea de enseñar una ciencia impura, con un utillaje verbal un tanto impreciso, con un vaivén entre la descripción de los hechos y la afirmación de ideales que, en verdad, tiene algo de navegación mareante. ¿A cuál de los dos polos dar preferencia, a los hechos, a los ideales?, ¿hasta qué punto debemos valorar para no trasmitir tan sólo a nuestros alumnos una información aséptica? y ¿hasta qué punto debemos abstenernos para no coaccionar su libertad de juicio, esto es, para no «hacer política» en las aulas?

Todo esto por lo que respecta al plano pedagógico. Pero también por lo que toca a nuestras conferencias y publicaciones se nos plantean acuciantes problemas. ¿Con qué concepto de «objetividad» científica trabajamos efectivamente?, ¿es éste un concepto tan sólo exigible a las ciencias naturales o ciencias puras según reza la vieja tradición? o ¿acaso hemos construido nuestro concepto operativo de objetividad sobre una plantilla científico-natural sin tener en cuenta las exigencias singulares que, en este orden, presentan las ciencias humanas y, en concreto, la jurisprudencia? Como ven presento un ramillete de preguntas que todos los docentes nos hemos planteado en algún momento y que cobra especial interés hoy, dado el alto nivel desvalorizador de nuestra compleja vida político-jurídica. Enfrentada hace tiempo a estas preguntas, aprovecho el sosiego que me permite este primer cuatrimestre sin docencia y la invitación a participar en esta sesión para exponerlas hoy aquí a los colegas asistentes.

${ }^{1}$ Ponencia presentada en el Congreso celebrado en la Universidad Católica de Valencia los días 20 y 21 de enero de 2016. 
En una carta - demasiado poco conocida-, Hannah Arendt nos recuerda que la verdad no es resultado de la reflexión, sino su condición previa y su punto de partida: sin una experiencia previa de la verdad es imposible desarrollar ninguna reflexión. La verdad no es relativa; por su propia naturaleza está al alcance de todos; es simple y evidente, a menudo, incluso, de una manera que duele ( $« \mathrm{~L} a$ verdad no siempre es bonita, pero el hambre de ella sí», afirmaba con razón la Premio Nobel de Literatura 1991, Nadine Gordimer). Cada vez que la gente se pregunta ¿qué es la verdad?, normalmente es porque la tiene delante — delante de las narices, si me permitís-, pero nos resulta muy incómodo reconocerlo y, como Pilatos, optamos por lavarnos las manos. Esta evidencia indiscutible de los primeros principios está presente desde su inicio tanto en la cultura occidental como en la cultura oriental [especialmente en la cultura China, en particular en Zhuang Zi o Hui Zi (340 a. C. aproximadamente), en la llamada época de los «Reinos Combatientes», largo periodo que transcurre entre el siglo v a. C y la unificación de China por la dinastía Qin en el año 221 a. C].

En igual medida digo que sin una experiencia previa de la justicia es imposible desarrollar ninguna reflexión sobre el Derecho. La justicia es para el jurista condición previa inexcusable ya desde el comienzo de nuestra formación y lo es a pesar del silencio que venimos manteniendo la mayoría de nosotros, ilustres profesores juristas. Criticamos en silencio y entre los íntimos lo que está aconteciendo en nuestras facultades de Derecho; denunciamos el vigente Plan de estudios de Bolonia y sus nefastos resultados; nos alarmamos por el creciente desmantelamiento de la universidad; nos irritamos con la lectura de decretos que, pisoteando el principio de irretroactividad, anulan derechos adquiridos; nos mostramos comprensivos con la nada o poca empatía mostrada por los ciudadanos con todo aquello que tenga que ver con el Derecho y con la justicia como institución; nos rebelamos, faltaría más, ante el incumplimiento de la ley y las sentencias de los tribunales, sobre todo, por parte de los poderosos; nos produce dolor la amarga realidad que padecen miles de emigrantes; nos sentimos impotentes ante el gravísimo problema del paro y la corrupción generalizada.

La lista de situaciones fácticas es, a estas alturas del siglo XXI, interminable. Mas, ¿cómo y con qué criterio medimos acerca de estas experiencias de injusticia tan cercanas a nuestra vida cotidiana?, ¿por qué cuando se nos enfrenta a una indecencia masiva procuramos por todos los medios permanecer como si no pasara nada, como si no fuera con noso- 
tros?, ¿cuándo seremos capaces de percatarnos de que la justicia es, ante todo, exposición y motivación del deber de respetar derechos ajenos (la frase socrática «quien comete injusticia es peor que padecerla» apunta en esta dirección) o, dicho de otra manera, que la justicia, en sentido estricto, sólo es patrimonio de aquellos que pueden dar o negar lo que pertenece a cada uno y mediante la cual se da a cada uno lo suyo?, ¿por qué el empeño de hacer desaparecer una imagen de la justicia que intente motivar al obligado — que en definitiva somos todos- sustituyéndola por la del legitimado?, ¿no estaremos construyendo y viviendo bajo el único punto de vista de «qué es lo mío», «qué hay de lo mío»? El romántico Goethe escribía con gran acierto en su novela Afinidades electivas [Die Wablverwandtschaften, 1809 (4. . ed. española, 2008)] que «por muy aislado que uno viva, se es, cuando menos se piensa, o deudor o acreedor», sobre todo porque el mínimo actuar humano genera constantemente débitos que exigen restitución. Lo preocupante es que, bajo el prisma exclusivamente individualista del legitimado, la referencia «al otro», elemento esencial de la justicia, se desdibuja y pierde su entidad.

Mas, antes de continuar, deseo dejar claro que, para mí, la filosofía del Derecho apunta a un principio último de justicia a partir del cual el Derecho adquiere su sentido, encuentra su unidad y determina su alcance. En consecuencia, defiendo:

1) que la justicia es el elemento esencial del Derecho, su ser existencial;

2) que la justicia, en tanto virtud ética y, por ende, hábito práctico adquirido para el cumplimiento y satisfacción del Derecho, requiere una actitud de constante y perpetua militancia que impida incurrir en los dos grandes peligros que también, constante y perpetuamente, la acechan: por un lado, la inhibición medrosa de aquellos que tienden a «desmedularla» convirtiéndola en mera asepsia técnica y, por otro, la política de poder, esto es, la política entendida no como voluntad de organizar la vida de la comunidad conforme a un ideal de vida, sino como lucha de equipos, lucha de adversarios o lucha ideológica basada en el odio;

3) que el Derecho es, en todas sus manifestaciones fenoménicas y no solo en la normativa, «una exigencia racional que brota de la naturaleza de la justicia» (algo destacado por Puy Muñoz), y

4) que, desde un planteamiento óntico-axiológico, defiendo, igualmente, un concepto material de Estado de Derecho en el que el poder del Estado es considerado vinculado a principios y valores 
superiores del Derecho, válidos para todos los ámbitos jurídicos, políticos y sociales, y en el que la actividad estatal, apoyándose en los procedimientos regulados por las leyes, esté orientada a la defensa de las garantías de los derechos y al establecimiento de una situación jurídica justa que asegure el orden de la vida en común.

Desde las coordenadas que acabo de concretar, a nadie extrañará que mi exposición esté dirigida a defender el lugar prioritario que la enseñanza de la justicia debe ocupar en la formación del jurista, dirigiendo mi defensa e invitando a mis ilustres colegas a llevarla a la práctica en sus respectivas tareas docentes e investigadoras. Y lo hago desde el convencimiento íntimo de que se trata de una tarea pendiente que no podemos posponer o relegar por más tiempo; no se trata de una tarea estética o de puro aggiornamento, sino de una tarea urgente en la que al menos, e insisto en lo de «al menos», los futuros jóvenes juristas que recién graduados salen de las aulas, ante la pregunta «¿qué piensas hacer cuando termines la carrera?», no respondan escogiéndose de hombros y exclamando «ufff» o con un «no sé lo que voy a hacer», sino que, con determinación, su respuesta sea «dedicaré mis conocimientos a luchar por la justicia».

Entonces y sólo entonces podrán llamarse en sentido pleno «juristas», entonces y sólo entonces nosotros, como docentes, habremos cumplido también plenamente con nuestra misión, y, tal vez, entonces y sólo entonces nos atreveremos a ofrecer respuestas razonadas públicamente a las preguntas que antes formulaba que claman sin dilación justicia. A esos efectos, nuestros jóvenes juristas necesitan conocer y comprender muy bien el orden jurídico; parafraseando a Puy Muñoz, «necesitan adquirir hábitos especulativos» que les permitan acceder a la theoria, poseer ciencia. «Ser jurista $[\ldots]$ presupone un hábito intelectual (dianoético) específico, consistente en saber realizar el orden social justo dentro de la sociedad [...] Ser jurista es estar en posesión del hábito intelectual dirigido a establecer, dentro de la comunidad humana, el orden social justo», escribía con gran precisión el venerable Javier Hervada. Pero, ante todo, lo que necesita el jurista es crear hábitos prácticos con los que decidir y resolver bien los conflictos prácticos en que los obliga a actuar cualquier profesión jurídica que desempeñen.

Para ello precisamos conjugar bien la inacción con la acción. Aclararé lo que quiero decir sirviéndome de un símil extraído del arte pictórico de Leonardo da Vinci. Giorgio Vasari (arquitecto del palacio de los Uffici en Florencia), en la que pasa por ser la primera historia del arte italiano, Vidas 
de los más excelentes arquitectos, pintores y escultores italianos (aparecida a mediados del siglo XVI), cuando describe la manera en que trabajaba Leonardo da Vinci en el mural de La última cena (1497) cuenta que el prior del convento dominico de Santa Maria delle Grazzie de Milán se irritaba diariamente por los largos intervalos de inacción que se permitía el pintor; ocurría que, en efecto, éste se pasaba medio día contemplando la pared sin tocar los pinceles. El prior, que hubiera querido ver a Leonardo trabajando de sol a sol, como lo hacían los jardineros que labraban la huerta, finalmente pidió al duque Sforza que instara al artista a apresurarse, a ser más constante en su trabajo. El duque preguntó a Leonardo sobre las razones de su lentitud y éste no dudó en ofrecerle una respuesta en la que desvelaba los secretos de su arte: «A menudo, dijo, los hombres de genio hacen mucho más cuanto menos actúan, pues tienen que meditar acerca de sus intervenciones y madurar en su espíritu las ideas perfectas que expresarán posteriormente reproduciéndolas con sus manos».

¿Diríamos que en el arte que cultivamos y enseñamos ocurre lo mismo? Veámoslo. Ante todo, en el arte de la jurisprudencia ocurre como en el arte pictórico: generalmente, la idea debe preceder al pincel. En este arte nuestro el conocimiento de la justicia debe acompañar al conocimiento de la ley positiva. Como el pintor, el jurista ha de «madurar en su espíritu» un conocimiento pleno de la justicia, y ha de hacerlo sin escamotear ninguno de sus múltiples e imprescindibles vértices o aspectos. Igualdad, simetría, reciprocidad, proporcionalidad, imparcialidad, son «elementos ontológicos estructurales que dotan de sentido y hacen posible la universalización de la norma jurídica», según Cotta. En efecto, sólo desde ese conocimiento pleno, el jurista será capaz de captar la trascendencia que para su oficio tienen las relaciones de justicia concretadas en la ley y los criterios para su valoración. ¿ $\mathrm{O}$ es que acaso nuestra misión es comparable a un solo de violín que interpretamos mientras aprendemos la técnica del instrumento a medida que vamos ejecutando la pieza?

La coincidencia entre el arte pictórico y el arte jurisprudencial respecto al valor superior de la «inacción» en este punto parece evidente, pero sólo y tan sólo en este punto, porque el objeto del arte, que nosotros los juristas cultivamos, es un polígono en el que se conjugan toda una serie de factores bien distintos a los del arte pictórico. Y claro está, ante un compuesto tan abigarrado como éste y tan difícil de captar en su unidad dinámica, la inteligencia, y a rastras de ella el lenguaje, sienten la tentación de operar reductivamente, esto es, de tachar alguno o algunos de los vértices del polígono, o de simplificar las cosas eliminando los satélites e incluso suprimiendo, o 
casi suprimiendo, el mismo astro en torno al que giran. En nuestro caso, tal es así que ese modo de operar reductivamente ha terminado eliminando ese astro sobre el que gira nuestro arte. Me refiero, claro está, al astro de la justicia. Es algo así como si un malabarista decidiera, para curarse en salud y evitar los posibles fallos, guardarse en el bolsillo alguno de los objetos que lanza al espacio. ¡Bien poco airoso recurso, sin duda!

El resultado de esa forma de operar reductivamente es que, sin variar la etiqueta «Derecho», se han ido alumbrando a lo largo de la historia unos cuerpos de conocimiento científico muy distintos, y eso explica no sólo la polisemia, sino yo diría que también la poca empatía existente con el arte que cultivamos; alumbramientos que no son sino el reflejo de otras tantas sinécdoques o retóricas sustituciones del todo por una de sus partes (iparece ser una de las tareas de la inteligencia humana el no poder descubrir casi nunca realidades nuevas sin incurrir en exageraciones y, consecuentemente también, en no graves olvidos!).

Hay que reconocer, y no me duelen prendas al hacerlo, que la comparación del malabarista falla a veces; el escamoteo de algunas de las bolas puede provocar una especie de absorbente concentración en las restantes, una mágica luz que lleva a descubrir nuevas y estupendas combinaciones. Pero, con todo, tendrá que venir después de cada descubrimiento una labor de corrección y «reencaje»; labor que sin duda debe comenzar en el nivel del análisis lingüístico. Hay que despegar a las palabras de aquellas realidades a las que ocasionalmente fueron adheridas o, de lo contrario, esas adherencias terminan desfigurando o anulando su rostro (el símil de la estatua de Glauco que utiliza Rousseau para ilustrar la renaturalización de la sociedad es muy elocuente).

Y precisamente esto es lo que no hace, en general, la ciencia del Derecho, que se sigue empeñando en salir del atasco uniendo al carro una yunta cuyo buey puntero siempre es la ley, vale decir el poder, factor del orden político-jurídico más accesible de conocer que los demás factores. Constreñida a estos límites y riesgos, la ciencia jurídica se desentiende de los más venerables problemas como es el de la justicia, o, cuando menos, los desenfoca para contemplarlos en escorzo, y siempre con la ley en un abusivo primer plano (tal vez por ello la ciencia jurídica es la más pretendida por el poder, mucho más cuando quienes la practican se dejan seducir por él; cuando los juristas se vuelven «orgánicos», cuando su trabajo intelectual es puesto «al servicio de», la traición a su profesión se ha consumado, como se ha consumado su servicio a la justicia; cuando esto ocurre el peligro se encuentra a las puertas, porque un sistema jurídico-político que 
no se halle en tensión crítica entre la ley positiva y lo prepositivo se puede transformar en una nihilista máquina letal).

Pero no terminan aquí las cosas, porque si atendemos a su carácter no ya de conocimiento, sino de realidad o acción, el proceso de fijaciones reductivas se hace mucho más patente. Desde la modernidad hasta hoy la jurisprudencia deja de ser un saber prudencial para convertirse en un saber presuntamente técnico y exacto. La historia de este giro es bien conocida. Para Aristóteles y la escolástica, política, derecho y técnica pertenecen al orden práctico, no al especulativo; pero mientras que, dentro del orden práctico, política y derecho corresponden al orden del obrar, la técnica corresponde al orden del hacer; es decir, mientras que la política y el derecho son pedagogías orientadas al uso de la libertad y a la formación del carácter según la virtud, la técnica es una destreza conducente a la fabricación de cosas exentas, esto es, desprendidas de nosotros, tanto si se trata de una casa, de una pintura, como de un poema.

Pues bien, para los modernos a partir de Maquiavelo, y más rotundamente a partir de Hobbes, el Estado y el Derecho pasan a ser como la casa, la pintura o el poema, es decir, pasan a ser unas realidades exentas, algo ya situado en el dominio del hacer más que en el dominio del obrar, y algo que, por tanto, debe medirse con baremos que tengan en cuenta el bonum operis («bien de la acción», que es el fin de la técnica) y no el bonum operantis («bien del hombre», que es el fin de la ética). Mientras que la jurisprudencia, especialmente desde los romanos, se movía en el ámbito de la prudencia utilizaba regulae arbitrarie, establecida por el hombre prudente para cada caso concreto y singular; ahora, en cambio, se hace omisión de la casuística moral para sustituirla por reglas determinadas y ciertas en aras a una seguridad jurídica que parece ser la panacea de todo el ordenamiento jurídico y en la que cada vez creen menos los ciudadanos. A resultado de todo lo cual la jurisprudencia, definitivamente, queda asimilada a la técnica.

Y claro está, de tal trasposición no podrá menos de seguirse un inexorable proceso de mímesis por el que el saber acerca del Derecho se va configurando según esquemas científico-naturales que tan sólo un razonamiento de tipo científico-natural permitirá construir con seguridad y precisión ese artefacto que tanto Estado como Derecho han venido a ser. Las antiguas alianzas con la ética parecen haberse consumado a estas alturas del siglo xxi. Diríamos que ahora ya no se trata de construir a Leviathan, sino de observarlo. Algo así como si el arquitecto se alejara de la casa que ha estado levantando y la comenzara a ver con la mirada neutra e inquisitiva con que el geólogo mira 
la montaña, hasta llegar a un punto en que se olvida de que la casa es obra suya, refundiéndola mentalmente con la continuidad del paisaje.

En suma, la jurisprudencia, que había comenzado siendo práctico-moral y que luego se había transformado en práctico-técnica, acaba en nuestros días convirtiéndose en especulativo-técnica. Especulativa en razón de su modo de conocer y técnica en razón de su objeto. Y qué ocurre, pues que con esta asimilación en aras al rigor científico la jurisprudencia se descoyunta y desvanece, víctima de una falsa asimilación a la ciencia natural, y con ello, lo que para la física, por ejemplo, es rigor científico, para la jurisprudencia y para los juristas apegados a ella es rigor mortis, puesto que cada ciencia tan sólo lo sigue siendo en la medida en que se mantenga fiel a la estructura de la realidad que considera. Y es que el monismo metódico de la ciencia natural o el more matemático o físico es la muerte para el conocimiento de cualquier ciencia humana y, muy especialmente, para una ciencia humana tan problemática, delicada y compleja como es la jurisprudencia.

Por último, un deseo: sin dilaciones y con decisión firme incorporemos ya a nuestros programas docentes un amplio tema sobre la justicia y sobre ese elemento regulador o corrector que es la equidad [en el que, con detenimiento, se estudie el libro $\mathrm{V}$, al que debe preceder una atenta lectura del libro VI, en particular los capítulos 1 a 4, de la Ética aristotélica y la Secunda Secundae de la Summa Theologica, especialmente las amplias cuestiones 57 a 79, donde, bajo el título «De Iure» («De lo Justo» o «Del Derecho»), Tomás de Aquino aborda el tema de la justicia jurídica].

La experiencia docente de tantos años me permite constatar el interés, el entusiasmo y, sobre todo, la satisfacción que experimentan nuestros jóvenes alumnos al conocer y comprender que el habitus, entendido como disposición adquirida para la acción, les va a permitir saber bien lo que es la igualdad en el caso concreto sobre el que han de decidir.

Conozco muy pocas cosas, es verdad, pero si algo he aprendido y tengo por cierto es que la creación de esos hábitos sólo puede proporcionárselo un pleno conocimiento de la justicia y que es a los iusfilósofos a quienes nos compete la tarea de enseñarlo. Es cierto que, como recientemente ha destacado Puy Muñoz, «el ejercicio ordinario y sano de los derechos lo llevan a cabo constantemente seres humanos justos», es más, «si ellos desaparecieran, la justicia, el Derecho y la ley se volatilizarían». Precisamente por esta razón debemos aspirar a que quienes realicen esas tareas sean cualitativamente excelentes juristas y cuantitativamente cada vez más numerosos, 
sólo así seremos capaces de aspirar a construir una vida en común más rica en valores y en afectos.

Si no lo hiciéramos nos veríamos tentados a aceptar la tesis que, apenas dos años antes de su muerte, proponía quien fuera catedrático de Derecho, decano, rector, ministro y, finalmente, magistrado-presidente del Tribunal Constitucional, Jiménez de Parga. En el año 2013 (El Mundo, 20 de abril, p. 15), y bajo el pseudónimo Secondant, firmaba el artículo titulado «Humillación del Derecho», en el que expresaba que «tanto en España como en otras naciones [...] los llamados juristas [...] no quieren ver en las normas jurídicas lo que perciben todos, incluso los faltos de instrucción en la materia [...] o sea, no quieren ver la realidad, sino la palabrería», y líneas después añadía, no sin tristeza, que «acaso sería conveniente y menos humillante para el Derecho suprimir la facultad de Derecho en las universidades y que todos fuéramos legos en la materia». El diagnóstico es exagerado y pesimista, pero bien sabemos que, aunque a veces la situación nos desborde incluso hasta el límite de preguntarnos qué hacemos aquí, el desánimo propio de tiempos difíciles debe y ha de ser superado con el esfuerzo de todos los implicados, es decir, de cada uno de nosotros. ¿Cómo? Pues, por ejemplo, al modo como recientemente ha recomendado un maestro iusnaturalista - de tan larga y prestigiosa trayectoria docente e investigadora - como es Puy Muñoz: aportando ideas que permitan llevar a cabo la transformación que necesita sufrir el docente, la doctrina jurídica que elabora y el entusiasmo que requiere esa transformación.

¡Justicia y Paz para todos en el año que comienza y... para los muchos que nos restan! 
